\title{
RESEARCH
}

\section{Isolation of Chromosome-Specific ESTs by Microdissection-Mediated cDNA Capture}

\author{
Edgardo Gracia, ${ }^{1-3}$ Michael E. Ray, ${ }^{1-3}$ Mihael H. Polymeropoulos, ${ }^{4}$ \\ Anindya Dehejia, ${ }^{4}$ Paul S. Meltzer, ${ }^{3}$ and Jeffrey M. Trent ${ }^{3,5}$
}

'Department of Human Genetics, The University of Michigan Medical School, Medical Science II M4708, Ann Arbor, Michigan 48109; ${ }^{3}$ Laboratory of Cancer Genetics, ${ }^{4}$ Laboratory of Genetic Disease Research, National Center for Human Genome Research, National Institutes of Health, Bethesda, Maryland 20892

Despite dramatic advances in the identification of human expressed sequence tags (ESTs), techniques that facilitate isolation of chromosome or chromosome band-specific ESTs would be of considerable value. This report demonstrates the feasibility of identifying chromosome-specific ESTs following microdissection of a single-copy chromosome region. For this study, a reduced complexity cDNA library was linkered and hybridized to normal human metaphase chromosomes. After stringency washes, the entire long arm of chromosome 6 (6q) was microdissected. Following PCR amplification using linker-specific primers, captured cDNAs were subcloned and 187 individual clones picked at random. These 187 clones were then sorted by filter cross-hybridization into 34 unique groups. Of these 34 groups, 19 (56\%) mapped to chromosome 6 by Southern blot. We identified three previously known genes, human cytovillin (ezrin) mapped previously to 6q25-26, human cardiac gap junction protein (connexin 43) mapped previously to 6q21-23.2 and prolyloligopeptidase, which had not been mapped previously. BLASTN identified three clone groups with homology to known ESTs and 12 representing novel cDNA sequences. Six of the groups were sublocalized to specific band regions of $6 \mathrm{q}$ using a chromosome 6 hybrid mapping panel, five representative clones were tested on Northern analysis to verify their expression, and finally, nine clones were mapped against the Gene bridge 4 reduction hybrid panel to confirm their genetic map location on 6q. These results demonstrate that microdissection of single-copy sequences has sufficient specificity for isolation of chromosome-specific cDNAs.

[The sequence data described in this paper have been submitted to GenBank under accession nos. U82773-U82791.]

The assembly of transcription maps from specific chromosomal regions is a major aim of the Human Genome Project. Recently, the large-scale efforts to map expressed sequence tags (ESTs) by radiationhybrid have added to our ability to assign transcribed sequences to specific chromosomal regions (Schueler et al. 1996). Unfortunately, despite this important effort, most ESTs have not yet been assigned to a chromosomal location, reducing their potential value as candidate genes for positional cloning efforts. Although it is currently possible to generate transcription maps of genomic regions covered by contigs of DNA clones (e.g., YACs and cosmids), the assembly of such maps requires gene isolation strategies including exon trapping and direct selection. Chromosome microdissection-based methods of gene selection, which do not require genomic clones from chromosomal regions of inter-

\footnotetext{
${ }^{2}$ These authors contributed equally to this work. ${ }^{5}$ Corresponding author.

E-MAIL jtrent@nchgr.nih.gov; FAX (301) 402-2040.
}

est, offer the potential to obtain ESTs in regions not yet covered by genomic contigs. Of perhaps more importance to this report, in many instances, is that unequivocal identification of chromosome bands affected by biologically interesting chromosome rearrangements (e.g., translocations, inversions, deletions, amplifications) may be impossible with conventional cytogenetic techniques. Chromosome microdissection provides a direct approach for the isolation of sequences from such sites of chromosome abnormality. Finally, application of this approach to isolate ESTs from specific chromosomal segments of less well-studied species could be of value.

Efforts to identify genes using chromosome microdissection in combination with hybrid selection can be divided into two different categories, depending on whether microdissection is carried out before or after selection. In the former case, the chromosomal region of interest is first microdissected and amplified with a degenerate primer. The resulting genomic sequences can then be immobi- 
lized on a solid support and used to hybrid-select cDNAs from the source of interest or, alternatively, the expressed sequences within the microdissected genomic DNA can be obtained by hybrid selection with immobilized cDNA (Su et al. 1994; Chen-Liu et al. 1995). This approach has been used successfully by our laboratory to isolate several genes from domains of DNA amplification in tumor cells (Su et al. 1994).

A second strategy based on microdissection is to hybridize a linkered cDNA library directly to metaphase chromosomes. The band region of interest is then microdissected, and region-specific cDNAs are amplified by linker-PCR and subcloned for analysis. Two recent publications (Hozier et al. 1994; Gracia

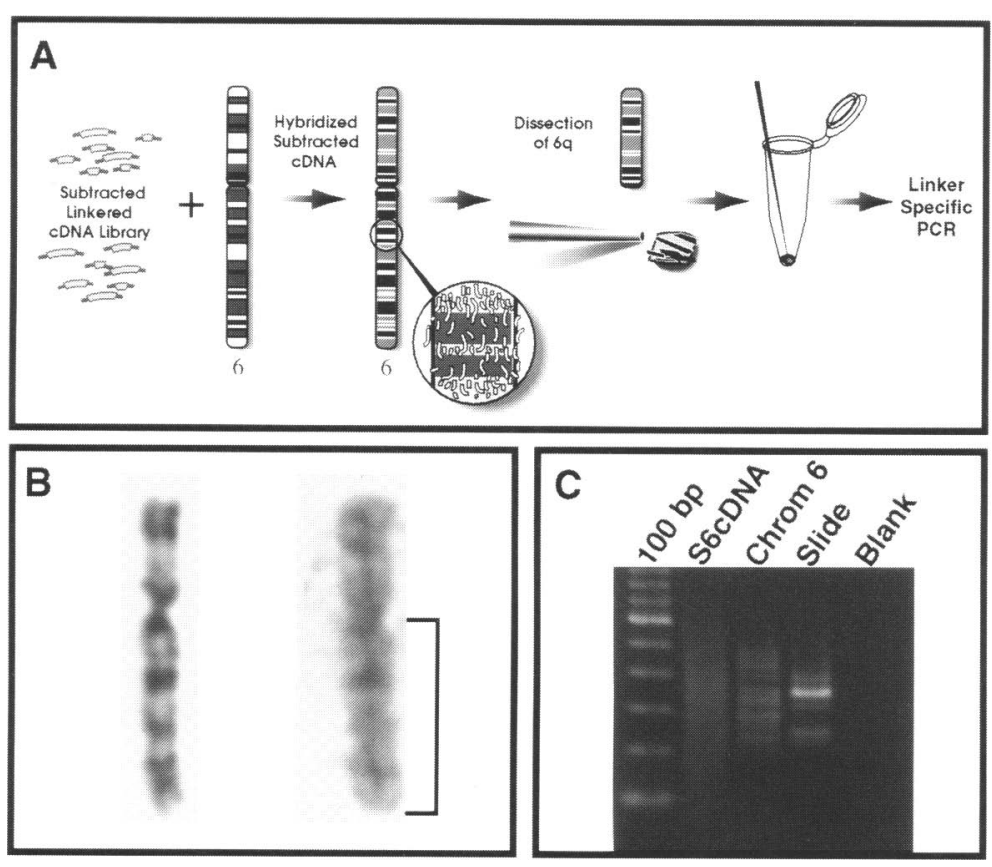

Figure 1 (A) Strategy for MMcC. Subtracted linkered cDNA was hybridized to normal G-banded metaphase chromosome spreads on a glass slide. The chromosomes were washed and stained with Giemsa, and 31 copies of $6 q$ were microdissected. The cDNAs bound to the microdissected material were then PCR amplified. (B) Identification and microdissection of chromosome 6. (Left) A G-banded chromosome 6 prior to hybridization; (right) the same chromosome 6 after cDNA hybridization, stringency washing, and Giemsa staining; microdissection of the long arm chromosome 6 is shown by the bracket. (C) Gel electrophoresis of recovered cDNAs. Thirty-one long arms of chromosome 6 and 29 blank slide regions were dissected and PCR amplified for 65 cycles (see Methods). Ten microliters of each PCR product were electrophoresed on a $2 \%$ agarose gel. (Lane 2, S6CONA) PCR of 0.5 pg of starting subtracted CDNA; (lane 3, chrom 6) the $6 q$ microdissection-captured cDNAs; (lane 4) scraping of the dissection module against blank regions adjacent to a dissected metaphase; (lane 5, Blank) a water control. et al. 1996) have suggested the utility of this approach in model systems. In our laboratory, this strategy has been used to isolate transcripts directly mplified DNA from human tumors, demontermed the hybridization of a linkered cDNA library some microdissection and cDNA recovery microdisal. 1996).

Our previous study demonstrated the efficacy of MMcC for the isolation of amplified genes encoded within homogeneously staining regions in human tumor cells. In this study we demonstrate the feasibility of utilizing $\mathrm{MMcC}$ on single-copy regions to recover cDNAs from the long arm of chromosome 6 (6q), a candidate region for a putative tumor suppressor genes involved in the development and progression of human malignancies (Trent et al. 1990). Because of this biological interest we selected a linkered cDNA library from a human melanoma cell line rendered nontumorigenic by the introduction of a normal copy of chromosome 6 following microcell-mediated chromosome transfer (Trent et al. 1990). Additionally, the library was reduced in complexity by subtractive hybridization with cDNA from the tumorigenic parental melanoma cell, a process that removed housekeeping genes as well as certain abundant sequences that contributed false positives in our previous study (e.g., ribosomal and mitochondrial sequences) (Gracia et al. 1996; Ray et al. 1996). Our results demonstrate conclusively that $\mathrm{MMcC}$ can be used successfully on singlecopy chromosome regions.

\section{RESULTS AND DISCUSSION \\ cDNA In Situ Hybridization and Microdissection}

PCR-amplified cDNA was hybridized to normal human lymphocyte metaphases, and after hybridization, a sequence of washes of increasing stringency were performed to remove nonspecifically bound cDNA (Fig. 1A-C). Thirty-one copies of $6 \mathrm{q}$ were then microdissected (Fig. 1B), and the hybridized cDNAs were recovered by 


\section{GRACIA ET AL.}

PCR with linker primers (Fig. 1A). After PCR, the captured cDNAs were analyzed by gel electrophoresis and compared to amplified cDNA from the pooled library and several controls (Fig. 1C). There is an apparent reduction in complexity between the starting and selected cDNA pools, with the bulk of the PCR product recovered ranging from 100 to 500 bp (Fig. 1C). The results of 29 mock dissections (done by touching a microneedle to an area of the slide devoid of chromatin) demonstrate the background nonspecific binding of cDNAs to the glass slide (Fig. 1C).

\section{CDNA Mapping and Cross-Hybridization}

The cDNAs recovered following microdissection were UDG-cloned, and 192 clones were picked individually. Individual cDNA inserts from 187 clones were tested to determine whether they derived from chromosome 6 by hybridization to mapping blots of DNA from a monochromosomal rodent-human hybrid containing chromosome 6 as well as human and rodent control DNAs. Concurrently, probes were hybridized to an array filter prepared from all 187 clones. In this manner, cDNA clones could be mapped to chromosome 6 and assigned to crosshybridizing groups avoiding redundant analysis.

The results (Table 1) demonstrated that the 187 clones could be placed into 34 cross-hybridizing groups (termed groups 1-34), containing from 1 to 15 clones per group. Of the 34 groups 19 (56\%) localized to chromosome 6 by Southern blot. Representative examples of five clones mapped to chromosome 6 are shown in Figure 2. Of the remaining groups, $2(6 \%)$ failed to give clear Southern signals, and $13(38 \%)$ gave clear signals in the normal human lane but did not appear to localize to chromosome 6. Overall, 99/187 (53\%) clones could be assigned to groups that mapped to chromosome 6 . The experimental design did not allow the estimation of the sensitivity of this technique, because the total number of sequences mapping to chromosome 6 was unknown.

To sublocalize captured cDNAs to a specific band region of chromosome 6, Southern and PCRbased analyses of each group were performed using DNA from a previously established chromosome 6 mapping panel (Pappas et al. 1995) (Fig. 3).

Higher resolution sublocalization of chromosome 6 cDNAs from nine groups was performed using the Genebridge 4 radiation hybrid panel (Walter et al. 1994; Hudson et al. 1995; A. Dehejia, E. LeRoy, R. Houlgatte, C. Auffray, and M. Polymeropoulos, in prep.) and statistical analysis using RHMAP-
PER software (D. Slonim, L. Stein, L. Kruglyak, and E. Lauder, unpubl.). Groups 25, 1, 919 15, 34, 4, 26, and 8 were all placed against the chromosome 6 marker framework with support for the correct marker order at 1000:1 (Fig. 3). These results by RH mapping correlate well regarding chromosome band location with those obtained by mapping panel, indicating that all chromosome 6-selected cDNAs captured by MMcC mapped within the microdissected region on $6 \mathrm{q}$.

\section{cDNA Sequencing and Northern Analyses}

Sequence data were obtained from each group mapping to chromosome 6 . For groups that had two or more cross-hybridizing clones, sequence was obtained from two clones from each group, and in all cases, both clones demonstrated identical sequence. Following BLASTN searching of GenBank (Altschul et al. 1990), group 8 sequences showed $100 \%$ identity to the gene described previously for human cytovillin or ezrin (VIL2), which had been mapped previously to 6q25-26 (Rao et al. 1994). The group 19 cDNA was shown to be identical to the human gene for the cardiac gap junction protein, connexin 43 (CX43), which was mapped previously to 6q2123.2 (Corcos et al. 1993). The previously described human gene for prolyl-oligopeptidase (Vanhoof et al. 1994) was $99 \%$ identical to the cDNA sequence of group 22. These data indicate that the prolyloligopeptidase gene (which had not been mapped previously) localizes to the long arm of chromosome 6 . Three groups demonstrated near identity to anonymous ESTs in current data bases, whereas 12 groups have no significant homology (Table 1). Group 4 showed sequence homology to a family of human LINE elements. We believe that the failure of several clones to match ESTs is a consequence of the procedure we used to linker the cDNA for hybridization. Specifically, whereas the vast majority of database EST (dbEST) entries originate from oligo(dT)-primed cDNAs and fall no more than 1-1.5 $\mathrm{kb}$ from the 3' mRNA terminus, the original cDNA in this study, although oligo(dT) primed, was then $A l u \mathrm{I}$ - or $A l u \mathrm{I} / R s a \mathrm{I}$-digested prior to PCR-linker ligation facilitating PCR amplification of upstream sequences (Ray et al. 1996).

Representative cDNA inserts from five groups mapping to chromosome 6 (groups 1, 2, 819 , and 22) were also hybridized to Northern blots to verify that they represented expressed sequences. Northern signals were apparent from total RNA from the original source cell line [UACC 903(+6)] for all five groups (Fig. 4). The combination of positive North- 
ISOLATION OF ESIS BY CHROMOSOME MICRODISSECTION

\begin{tabular}{|c|c|c|c|c|}
\hline Group & Clones & Chromosome 6 & Sublocalization & Sequence \\
\hline 1 & 15 & + & $6 q 11-12$ & novel \\
\hline 2 & 7 & + & & novel \\
\hline 3 & 9 & - & & \\
\hline 4 & 3 & + & $6 q 23.3-q$ ter & LINE \\
\hline 5 & 11 & + & & novel \\
\hline 6 & 8 & - & & \\
\hline 7 & 13 & - & & \\
\hline 8 & 6 & + & $6 q 25-26$ & VIL2 (J05021) \\
\hline 9 & 9 & + & $6 q 21-23$ & EST (R28143) \\
\hline 10 & 12 & - & & \\
\hline 11 & 6 & - & & \\
\hline 12 & 10 & + & & novel \\
\hline 13 & 8 & - & & \\
\hline 14 & 2 & + & & novel \\
\hline 15 & 5 & + & $6 q 21-23$ & novel \\
\hline 16 & 3 & smear & & \\
\hline 17 & 7 & N.D. & & \\
\hline 18 & 3 & - & & \\
\hline 19 & 2 & + & $6 q 21-23.2$ & CX43 (X52947) \\
\hline 20 & 11 & + & & novel \\
\hline 21 & 6 & - & & \\
\hline 22 & 3 & + & & p-oligopeptidase \\
\hline 23 & 2 & - & & \\
\hline 24 & 6 & - & & \\
\hline 25 & 4 & + & $6 q 11-12$ & novel \\
\hline 26 & 2 & + & $6 q 23.3$-qter & novel \\
\hline 27 & 1 & + & $6 q 21-23$ & novel \\
\hline 28 & 2 & - & & \\
\hline 29 & 1 & - & & \\
\hline 30 & 3 & + & & EST (H21591) \\
\hline 31 & 2 & + & & novel \\
\hline 32 & 2 & - & & \\
\hline 33 & 2 & + & & EST (R60730) \\
\hline 34 & 1 & + & $6 q 22$ & novel \\
\hline Total 34 & 187 & $\begin{array}{l}19 / 34 \\
(56 \%)\end{array}$ & & \\
\hline
\end{tabular}

Summary chromosome 6q MMcC-captured cDNAs. Clones (187) were sorted into 34 cross-hydridizing groups containing from 1 to 15 clones per group. The groups were mapped to chromosome 6 by Southern blotting and sublocalized on chromosome 6 by PCR of a chromosome 6 somatic cell radiation hybrid panel. Clones from each chromosome 6 group were sequenced and searched for significant homology with public sequence databases (accession numbers indicated). Asterisks indicate previously assigned localizations for VIL2 and CX43 (Corcos et al. 1993; Rao et al. 1994)

ern signals from several recovered clones, sequence identification of known genes mapping to $6 \mathrm{q}$, and homology to previously recognized ESTs strongly suggests that the microdissection-captured sequences represent expressed genes.

\section{Choice of cDNA Source}

Our choice of cDNA in this study was based in part on our earlier results of $\mathrm{MMcC}$, where isolation of genes from an amplified cell line provided reasonably specific (50\%-70\%) recovery of cDNAs but included repetitive or highly abundant transcripts (mitochondrial, ribosomal, highly transcribed genes). Therefore, a cDNA library of reduced complexity was utilized. In this study this library was selected to contain genes potentially relevant to the chromosome 6-mediated suppression of tumorige- 
GRACIA ET AL.

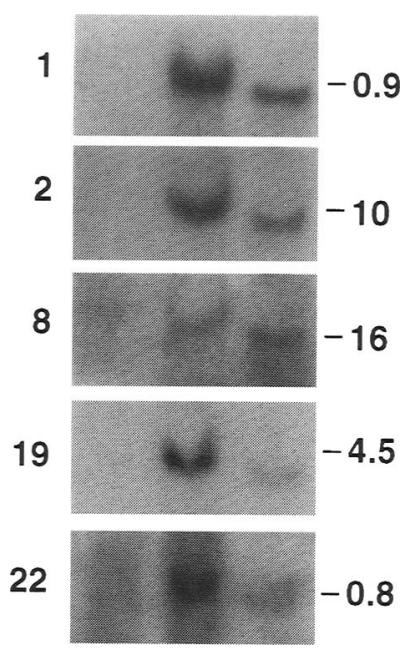

Figure 2 Representative hybridization signal by Southern mapping for CDNAs from groups 1, 2, 8 19, and 22. CDNA inserts from individual clones were PCR amplified and labeled for use as probes against EcoRIdigested genomic DNA from Chinese hamster ovary (CHO) cells, $\mathrm{CHO}$ plus human chromosome 6 monochromosome hybrid cells $(\mathrm{CHO}+6)$, and normal human placenta DNA.

nicity observed in human malignant melanoma cells. This illustrates an advantage of $\mathrm{MMcC}$, primarily the ability to select the cDNA source enriched for expressed genes of biologic interest. For example, the potential to use libraries that are cell or tissue specific or expressed in a specific spatial or temporal pattern is a particularly important feature of this and other hybrid selection-based approaches.

\section{Single-Copy MMcC Specificity and Sensitivity}

Finally, these results demonstrate that the specificity of $\mathrm{MMcC}$ in identifying genes from the dissection of single-copy chromosomal regions (53\%) is roughly equivalent to that of our previous results using this approach to identify genes from an amplified DNA domain (50\%-70\%) (Gracia et al. 1996). The modified strategy used in this report, which made use of a reduced complexity subtracted cDNA pool for hybridization, also appeared to eliminate ribosomal or mitochondrial sequences among the false positives.

At the current time, there is currently no quantitative data as to the absolute level of sensitivity of chromosome microdissection based on selection approaches. Ongoing efforts are under consideration to address $\mathrm{MMcC}$ sensitivity and will require experiments utilizing a variety of cDNA sources hybrid- ized to chromosomal regions for which detailed transcription mapping information is available. As a crude estimate of sensitivity, we examined the complexity of the original cDNA library (Ray et al. 1996) relative to ESTs identified within our MMcC selection procedure.

\section{METHODS}

\section{Subtracted cDNA}

PCR-linkered cDNA from a chromosome 6-suppressed subline of the tumorigenic human melanoma cell line UACC 903 (Trent et al. 1990) was generated as described previously (Ray et al. 1996). Sufficient cDNA for hybridization to metaphase chromosomes was generated by PCR amplification in a $100-$ $\mathrm{ml}$ PCR reaction with $50 \mathrm{mM} \mathrm{KCl,} 1.5 \mathrm{mM} \mathrm{MgCl}_{2}, 10 \mathrm{~mm}$ Tris $\mathrm{HCl}(\mathrm{pH} 8.4), 250 \mathrm{~mm}$ each dNTP, $1 \mathrm{~mm}$ SP2 primer (5'CTCTTGCTTGAATTCGGACTA-3'), 2.5 units of Taq polymerase, and 10 ng of $\$ 6 \mathrm{cDNA}$ (Ray et al. 1996) template at $96^{\circ} \mathrm{C}$ for $5 \mathrm{~min}, 20$ cycles of $94^{\circ} \mathrm{C}$ for $1 \mathrm{~min}, 52^{\circ} \mathrm{C}$ for $1 \mathrm{~min}, 72^{\circ} \mathrm{C}$ for $1 \mathrm{~min}$, and $4^{\circ} \mathrm{C}$ soak overnight. The PCR product was purified using a QUIquick-spin column (Quiagen), ethanol precipitated, resuspended in $5 \mathrm{ml}$ of TE buffer, and quantitated for hybridization.

As an unrefined estimate of the quality of the original subtracted library (prior to hybridization), a total of $768 \mathrm{cD}$ NAs were sequenced and self-BLASTed to estimate the number of unique clones. A total of $658 / 768(86 \%)$ was unique by this criteria. As shown in Table 1, the frequency of the recovered clones that mapped to chromosome 6 following MMcC (as assessed by cross-hybridization) ranged from 15/187 (8.0\%) to $1 / 187(0.05 \%)$.

\section{Hybridization}

Normal human metaphase chromosomes were prepared from cultured peripheral blood lymphocytes as described previously (Trent and Thompson 1986). The slides were aged at room temperature for 1 week prior to trypsin-Giemsa banding. Metaphases were photographed, and their positions noted prior to cDNA hybridization. A hybridization solution without formamide was prepared (Gracia et al. 1996) containing $630 \mathrm{ng}$ of subtracted cDNA in $30 \mathrm{ml}$ of solution used under a 50-mm coverslip. The coverslips were sealed with rubber cement and allowed to dry completely. Slides were then exposed to a $100^{\circ} \mathrm{C}$ steam bath to simultaneously denature both the metaphase chromosomes and probe in situ. The cDNA was allowed to hybridize for $72 \mathrm{hr}$ at $65^{\circ} \mathrm{C}$. The slides were washed twice for $5 \mathrm{~min}$ in $2 \times$ SSC, $0.01 \%$ Tween 20 at $65^{\circ} \mathrm{C}, 5 \mathrm{~min}$ once in $1 \times \mathrm{SSC}, 0.01 \%$ Tween 20 , at $65^{\circ} \mathrm{C}$, and 5 min once in $0.5 \times \mathrm{SSC}, 0.01 \%$ Tween 20 at $65^{\circ} \mathrm{C}$. The slides were then stained in $6 \%$ Giemsa (Gurr) in phosphate buffer (Gracia et al. 1996). Slides were stored at $-80^{\circ} \mathrm{C}$ until microdissection.

\section{Microdissection and cDNA Amplification}

Microdissection of the cDNA-hybridized chromosomes was performed using a glass microneedle controlled by a hydraulic micromanipulator (Narashige) as described previously (Melt- 
ISOLATION OF ESTS BY CHROMOSOME MICRODISSECTION

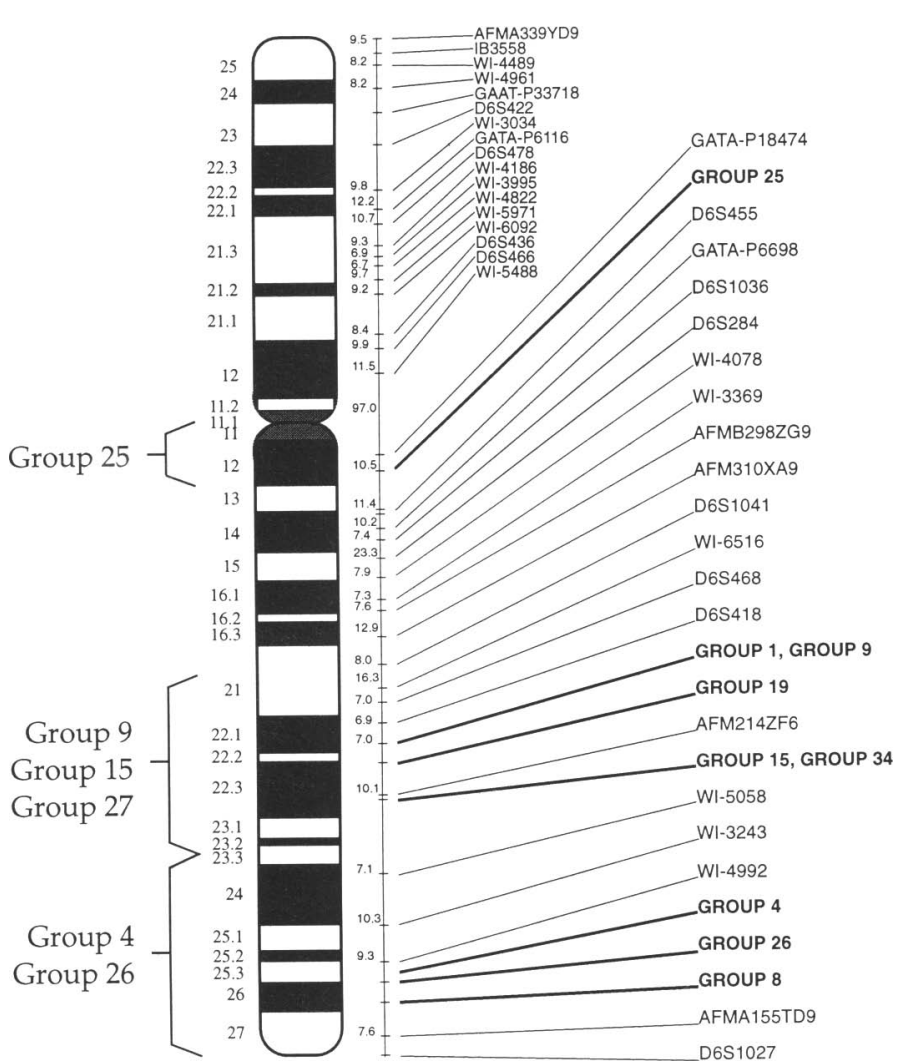

Figure 3 PCR sublocalization of chromosome 6 microdissection-captured CDNAs. (Center) Identification of human chromosome 6; (left) six cDNA groups successfully sublocalized by PCR using a human/rodent hybrid mapping panel for chromosome 6; (right) high-resolution mapping against the chromosome 6 marker framework was performed using the Genebridge 4 radiation hybrid panel (Walter et al. 1994; Hudson et al. 1995; A. Dehijiaa, E. LeRoy, R. Houlgatte, C. Auffray, and M. Polymeropoulos, in prep.) with statistical analysis using RHMAPPER software (D. Slonim, L. Stein, L. Kruglyak, and E. Lauder, unpubl.). Each cDNA group was placed against the chromosome 6 framework with support for the correct order of $>1000: 1$ (see text).

zer et al. 1992). The long arm was dissected from 31 copies of chromosome 6 , with the microdissected material placed into a $3.5-\mathrm{ml}$ collection drop containing $65 \mathrm{~mm} \mathrm{KCl}, 1.95 \mathrm{~mm}$ $\mathrm{MgCl}_{2}, 13 \mathrm{~mm}$ Tris- $\mathrm{HCl}(\mathrm{pH} 8.4)$ and heated to $94^{\circ} \mathrm{C}$ for 30 min. $1.5 \mathrm{ml}$ containing the remaining PCR components was added to the collecting drop prior to cycling. The final PCR conditions were $50 \mathrm{mM} \mathrm{KCl}, 1.5 \mathrm{mM} \mathrm{MgCl}_{2}, 10 \mathrm{mM}$ Tris- $\mathrm{HCl}$ (pH 8.4), $200 \mathrm{~mm}$ of each dNTP, 0.25 units of Taq polymerase, and $2.5 \mathrm{~mm}$ SP2 primer for a preamplification step of 15 cycles of $1 \mathrm{~min}$ at $94^{\circ} \mathrm{C}, 1 \mathrm{~min}$ at $52^{\circ} \mathrm{C}$, and $1 \mathrm{~min} 72^{\circ} \mathrm{C}$ in a $5-\mathrm{ml}$ volume. The volume was increased to $55 \mathrm{ml}$ with 1.25 units of Taq polymerase, $200 \mathrm{~mm}$ of each dNTP, $2.5 \mathrm{~mm} \mathrm{SP2,50 \textrm {mm }}$ $\mathrm{KCl}, 1.5 \mathrm{~mm} \mathrm{MgCl}_{2}, 10 \mathrm{~mm}$ Tris- $\mathrm{HCl}(\mathrm{pH} 8.4)$ and amplified for 30 more cycles with a final $10 \mathrm{~min}$ at $72^{\circ} \mathrm{C}$ extension.

\section{Cloning and Sequencing of cDNAs}

The microdissection-selected cDNAs were prepared for UDG cloning. Four milliliters of cDNA was amplified for 20 cycles using CUA-SP2 primer (5' -CUACUACUACUACTCTTGCTTGAATTCGGACTA-3') under the PCR conditions for stock cDNA amplification described above. The PCR products were purified with a QUIquick-spin column (Quiagen) and ethanol precipitated. Fifty nanograms of cDNA was mixed with $50 \mathrm{ng}$ of pAMP10 nondirectional UDG cloning vector (GIBCO-BRL). The mix was incubated with uracil DNA glycosylase and transformed into MaxEfficiency DH10B cells according to the manufacturer's protocol (GIBCO-BRL). Transformant colonies (192) were picked individually into 96-well plates containing $200 \mathrm{ml}$ of Luria broth plus $100 \mathrm{mg} / \mathrm{ml}$ of ampicillin in each well and grown overnight at $37^{\circ} \mathrm{C}$. PCR using SP2 primers (described above) on $1 \mathrm{ml}$ of culture was used to recover the cDNA insert from each clone. Five clones were eliminated because of double inserts (two colonies accidentally picked). cDNA clones of interest were plasmid prepped and sequenced (SeqWright, Houston, TX).

\section{Southern, cDNA Array, and Northern Analyses}

Genomic DNA from Chinese hamster ovary cells (CHO), normal human placental tissue, and $\mathrm{CHO} /$ human chromosome 6 hybrid D113JA (Pappas et al. 1995) was prepared as described (Stauss 1994). DNA was digested with EcoRI, Southern blotted as described previously (Ray et al. 1994), and probed with individually labeled cDNA inserts. PCR-amplified cDNA inserts from each of the clones were dot blotted onto nylon membranes in duplicate for concurrent hybridization with the mapping Southern blots. Total cellular RNA was prepared from UACC 903(+6) for Northern analyses as described previously (Ray et al. 1996). Blots were then exposed to Kodak $\mathrm{X}$-OMAT AR autoradiography film at $-80^{\circ} \mathrm{C}$ for $1-7$ days.

\section{Sublocalization by PCR on Chromosome 6 Hybrid Mapping Panel}

Specific primers were designed for each recovered cDNA group to sublocalize sequences along $6 \mathrm{q}$ using a chromosome 6 radiation-reduced hybrid mapping panel (Pappas et al. 1995). EG4, 5'-TCACCTGTCAGGATGGCTATCATTG-3'; and MR4, 5'-GCTGCACCATTTTGCATTCCC3' for group 4; EG9, 5'-CGTAATGCTGAGTACATCTGCCAG3', and MR9, 5'-CTTCCACTACGAAAAAAGGGG-3' for group 9; EG15，5'-GCACTTTGGACTCTGTGTTCAGGG-3', and MR15, 5'-TTGCTCTCGCCACTATCCTCTGAC-3' for group15; EG25, 5'-TTGGGGAAGGAGCAAACAACC-3', and MR25, 5'GTCTTGTGGAACAGTTTCAGGGATG-3' for group 25; EG26, 5'-AACTTGACTGCTCACACGGTTTG-3', and MR26, 5'CTTGACCAAATCATCTCTTGCAGG-3' for group 26; EG27, 5'-TCATCTTCTGACCATTGACGAAG-3', and MR27, 5'GGCTTCTCTGCATTCCAGTG-3' for group 27.

PCR was carried out in a $20-\mathrm{ml}$ volume with $100 \mathrm{ng}$ of template DNA from the hybrid panel members, 0.5 units of Taq polymerase, $200 \mathrm{~mm}$ of each dNTP, $5 \mathrm{~mm}$ of each primer, $50 \mathrm{mM} \mathrm{KCl}, 1.5 \mathrm{mM} \mathrm{MgCl}_{2}$, and $10 \mathrm{mM}$ Tris-HCl (pH 8.4). Thermocycling was performed with a modified Touchdown PCR strategy (Don et al. 1991). Briefly, cycling started with a 3 -min $94^{\circ} \mathrm{C}$ denaturation step and a 2 -min $72^{\circ} \mathrm{C}$ annealingextension step. This was followed by 16 cycles with a 1-min 


\section{GRACIA ET AL.}

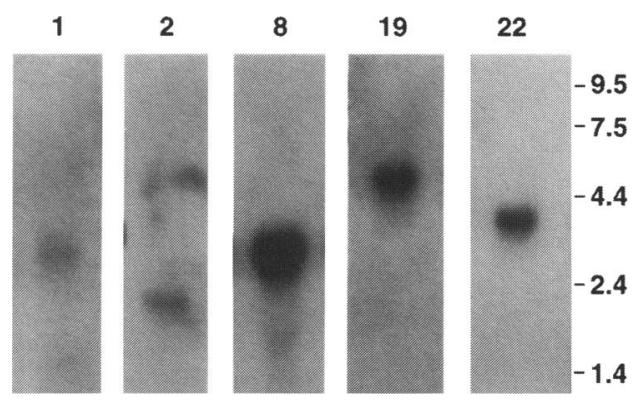

Figure 4 Representative Northern data from chromosome 6 cDNAs from groups 1, 2, 819 , and 22. CDNA inserts from individual clones were PCR amplified and labeled for use as probes against Northern blots of total cellular RNA (exposure time 1-7 days) from the source cell line UACC $903(+6)$ (Trent et al. 1990).

$94^{\circ} \mathrm{C}$ denaturation step, an annealing step starting at $72^{\circ} \mathrm{C}$, and decreasing in temperature by $1^{\circ}$ with each cycle to $56^{\circ} \mathrm{C}$, and a $1-\min 72^{\circ} \mathrm{C}$ extension step. The PCR reactions were then cycled 30 times at $94^{\circ} \mathrm{C} 1 \mathrm{~min}, 55^{\circ} \mathrm{C}$ for $1 \mathrm{~min}, 72^{\circ} \mathrm{C}$ for $1 \mathrm{~min}$ with a final $10-\mathrm{min} 72^{\circ} \mathrm{C}$ extension. Conventional agarose gel electrophoresis was used to analyze the PCR products. Higher resolution mapping of the $\mathrm{MMcC}$ recovered chromosome 6 ESTs was performed using the Genebridge 4 radiation hybrid panel (Walter et al. 1994; Hudson et al. 1995; A. Dehijiaa, E. LeRoy, R. Houlgatte, C. Auffray, and M. Polymeropoulos, in prep.). Statistical analysis of the data was performed using the RHMAPPER software package (D. Slonim, L. Stein, L. Kruglyak, and E. Lander, unpubl.). The cDNAs were placed against the chromosome 6 framework map with support for the correct order $>1000: 1$.

\section{ACKNOWLEDGMENTS}

We acknowledge the graphics assistance of Daryl Leeja.

The publication costs of this article were defrayed in part by payment of page charges. This article must therefore be hereby marked "advertisement" in accordance with 18 USC section 1734 solely to indicate this fact.

\section{REFERENCES}

Altschul, S.F., W. Gish, W. Miller, E.W. Myers, and D.J. Lipman. 1990. Basic local alignment search tool. J. Mol. Biol. 215: $403-410$.

Chen-Liu, L.W., B.C. Huang, J.M. Scalzi, B.K. Hall, K.R. Sims, L.M. Davis, P.D. Siebert, and J.C. Hozier. 1995. Selection of hybrids by affinity capture (SHAC): A method for the generation of cDNAs enriched in sequences from a specific chromosome region. Genomics 30: 388-392.

Corcos, I.A., E.U. Meese, and R. Loch-Caruso. 1993. Human connexin 43 gene locus, GJA1, sublocalized to band 6q21-q23.2. Cytogenet. Cell Genet. 64: 31-32.

Don, R.H., P.T. Cox, B.J. Wainwright, K. Baker, and J.S.
Mattick. 1991. "Touchdown" PCR to circumvent spurious priming during gene amplification. Nucleic Acids Res. 19: 4008 .

Gracia, E., U. Fischer, A. ElKahloun, J.M. Trent, E. Meese, and P.S. Meltzer. 1996. Isolation of genes amplified in human cancers by microdissection mediated cDNA capture. Hum. Mol. Genet. 5: 595-600.

Hozier, J., R. Graham, T. Westfall, P. Siebert, and L. Davis. 1994. Preparative in situ hybridization: Selection of chromosome region-specific libraries on mitotic chromosomes. Genomics 19: 441-447.

Hudson, T., L. Stein, S. Gerety, J. Ma, A. Castle, J. Silva, D. Slonim, R. Baptista, L. Kruglyak, S. Xu, X. Hu, A. Colbert, C. Rosenberg, M.P. Reeve-Daly, S. Rozen, L. Haui, X. Wu, C. Verstergaard, K. Wilson, J. Bae, S. Maitra, S. Ganiatsas, C. Evans, M. DeAngelis, K. Ingalls, R. Nahf, L. Horton, M. Oskin, A. Collymore, W. Ye, V. Kouyoumjian, I. Zernsteva, J. Tarn, R. Devine, D. Courtney, M. Renaud, H. Nguyen, T. O'Connor, C. Fizames, S. Faure, G. Gyapay, C. Dib, J. Morisette, J. Orlin, B. Birren, N. Goodman, J.Weissenbach, T. Hawkins, S. Foote, D. Page, and E. Lander. 1995. An STS-based map of the human genome. Science 270: 1945-1954.

Meltzer, P.S., X.-Y. Guan, A. Burgess, and J.M. Trent. 1992. Generation of region specific probes by chromosome microdissection: A novel approach to identify cryptic chromosomal rearrangements. Nature Genet. 1: 24-28.

Pappas, G.J., E. Thompson, A. Burgess, A. Geenwood, and J.M. Trent. 1995. Generation and molecular cytogenetic characterization of a radiation-reduction panel for human chromosome 6. Cytogenet. Cell Genet. 69: 201-206.

Rao, P.H., V.V.V.S. Murty, G. Gaidano, R. Hauptschein, R. Dalla-Favera, and R.S.K. Chaganti. 1994. Subregional mapping of 8 single copy loci to chromosome 6 by fluorescence in situ hybridization. Cytogenet. Cell Genet. 66: $272-273$.

Ray, M.E., X.-Y. Guan, M.L. Slovak, J.M. Trent, and P.S. Meltzer. 1994. Rapid detection, cloning, and molecular cytogenetic characterisation of sequences from an MRP-encoding amplicon by chromosome microdissection. Br. J. Cancer 70: 85-90.

Ray, M.E., Y.S. Su, P.S. Meltzer, and J.M. Trent. 1996. Isolation and characterization of genes associated with chromosome 6-mediated tumor suppression in human malignant melanoma. Oncogene 12: 2527-2533.

Schuler, G., M. Boguski, E. Stewart, L. Stein, G. Gyapay, K. Rice, R. White, P. Rodriguez-Tomé, A. Aggarwal, E. Bajorek, S. Bentolila, B. Birren, A. Butler, et al. 1996. A gene map of the human genome. Science 274: 540-546.

Stauss, W.M. 1994. Preparation of genomic DNA from mammalian tissue. In Current protocols in molecular biology. (ed. F.M. Ausubel), Vol. 1, Suppl. 25, pp. 2.2.1-2.2.3. Greene Publishing Associates/John Wiley, New York, NY. 
Su, Y.A., J.M. Trent, X.-Y. Guan, and P.S. Meltzer. 1994.

Direct isolation of genes encoded within a homogeneously staining region by chromosome microdissection. Proc. Natl. Acad. Sci. 91: 9121-9215.

Trent, J. and F. Thompson. 1987. Methods for chromosome banding of human and experimental tumors in vitro.

Methods Enzymol. 151: 267-269.

Trent, J.M., E.J. Stanbridge, H.L. McBride, E.U. Meese, G. Casey, D.E. Araujo, C.M. Witkowski, and R.B. Nable. 1990. Tumorigenicity in human melanoma cell lines controlled by introduction of human chromosome 6 . Science

247: 568-571.

Vanhoof, G., F. Goossens, L. Hendriks, I. De Meester, D. Hendriks, D. Vriend, C. Van Broeckhoven, and S. Scharpe. 1994. Cloning and sequence analysis of the gene encoding human lymophocyte prolyl endopeptidase. Gene

149: $363-366$.

Walter, M., D. Spillett, P. Thomas, J. Weissenbach, and P. Goodfellow. 1994. A method for constructing radiation hybrid maps of whole genomes. Nature Genet. 7: 22-28.

Received September 5, 1996; accepted in revised form December $17,1996$. 


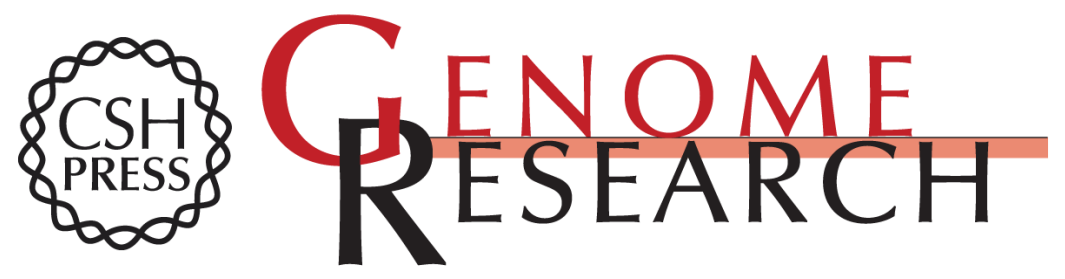

\section{Isolation of chromosome-specific ESTs by microdissection-mediated cDNA capture.}

E Gracia, M E Ray, M H Polymeropoulos, et al.

Genome Res. 1997 7: 100-107

Access the most recent version at doi:10.1101/gr.7.2.100

References This article cites 18 articles, 4 of which can be accessed free at:

http://genome.cshlp.org/content/7/2/100.full.html\#ref-list-1

\section{License}

Email Alerting Receive free email alerts when new articles cite this article - sign up in the box at the Service top right corner of the article or click here.

\section{Affordable, Accurate Sequencing.}

To subscribe to Genome Research go to: https://genome.cshlp.org/subscriptions 